\title{
Efeito da substituição de feno de capim-tifton 85 por silagem de milho no consumo, na digestibilidade dos nutrientes e no desempenho de novilhos mestiços Limousin ${ }^{1}$
}

\author{
Viviane Glaucia de Souza ${ }^{2}$, Odilon Gomes Pereira ${ }^{3}$, Sebastião de Campos Valadares Filho ${ }^{3}$, Karina \\ Guimarães Ribeiro ${ }^{4}$, Dalton Henrique Pereira ${ }^{5}$, Paulo Roberto Cecon ${ }^{6}$, Bruno Ceolin da Silva ${ }^{7}$ \\ ${ }^{1}$ Parte da tese de doutorado do primeiro autor apresentada ao Programa de Pós-Graduação em Zootecnia da Universidade Federal de Viçosa \\ - UFV. Bolsista do CNPq. \\ 2 FACIG, Rua Desembargador Alonso Starling, 111, Centro, Manhuaçu - MG, 36900-000. \\ ${ }^{3}$ Depto. de Zootecnia/UFV. Bolsista do CNPq. \\ 4 Depto. de Zootecnia/UFVJM, Diamantina, MG \\ ${ }^{5}$ Doutorando em Zootecnia/UFV. Bolsista da CNPq. \\ ${ }^{6}$ Depto. de Informática/UFV. Bolsista do CNPq. \\ 7 Mestre em Zootecnia.
}

RESUMO - Avaliaram-se o consumo e a digestibilidade dos nutrientes, o ganho de peso e a conversão alimentar de bovinos de corte recebendo dietas contendo feno de capim-tifton 85 e silagem de milho nas proporções 100:0; 68:32; 35:65 e 0:100, com base na MS. Foram utilizados 19 animais mestiços Limousin x Zebu, não-castrados, com PV inicial de $301 \mathrm{~kg}$, distribuídos em um delineamento inteiramente casualizado. A relação volumoso:concentrado foi de 58:42, com base na MS. O ensaio teve duração de 99 dias, sendo 15 dias de adaptação e três períodos de 28 dias para avaliações. Para determinação da excreção fecal, utilizou-se a fibra em detergente ácido indigestível (FDAi) como indicador.Os consumos médios de MS, MO, PB, CT e FDN apresentaram efeito quadrático em função de níveis crescentes de silagem de milho. Para os consumos de MS e MO, estimaram-se valores máximos de 7,52 e 7,08 kg/dia para os níveis de 61,13 e 61,78\%, respectivamente, de silagem de milho no volumoso. As digestibilidades aparentes de MS, MO e FDN não foram influenciadas pelos níveis de silagem de milho no volumoso. O ganho de peso médio diário aumentou de forma linear e a conversão alimentar decresceu, também de forma linear, com o incremento da proporção de silagem de milho no volumoso das dietas. A silagem de milho como constituinte do volumoso da dieta, na proporção de $61 \%$, proporcionou máximo consumo de MS. O ganho de peso aumentou 4,82 g/dia para cada unidade de silagem de milho adicionada ao volumoso da dieta para novilhos mestiços Limousin.

Palavras-chave: confinamento, conversão alimentar, fibra em detergente ácido indigestível

\section{Effect of replacing Tifton 85 hay with corn silage on intake, digestibility, and performance of crossbred Limousin x Zebu bulls}

\begin{abstract}
Intake, digestibility of nutrients, daily gain, and feed conversion were evaluated in beef cattle receiving diets containing Tifton 85 hay and corn silage in the following proportions (\% forage DM): 100:0, 68:32, 35:65, and 0:100. A forage:concentrate ratio of 58:42 (\% diet DM) was used. Nineteen crossbred Limousin x Zebu bulls averaging $301 \mathrm{~kg}$ of initial body weight were allotted to completely randomized design. The trial lasted 99 days with 15 days for diet adaptation and three experimental periods of 28 days. Indigestible acid detergent fiber was used as an internal marker to estimate fecal excretion. The mean daily intakes of DM, OM, CP, TC, and NDF all responded quadratically by increasing the corn silage level in the diet. The quadratic maxima for both DM and OM intakes were 7.52 and $7.08 \mathrm{~kg} /$ day at 61.13 and $61.78 \%$ of corn silage in the forage fraction of the diet, respectively. The apparent total tract digestibilities of DM, OM, and NDF were not affected by the proportion of corn silage in the diet. However, average daily gain and feed conversion increased and decreased linearly, respectively, when the proportion of corn silage in the forage portion of the diet was increased from 0 to $100 \%$. The weight gain of crossbred Limousin $\mathrm{x}$ Zebu bulls increased $4.82 \mathrm{~g} /$ day per each unit of corn silage included in the diet.
\end{abstract}

Key Words: feedlot, feed conversion ratio, indigestible acid detergent fiber

\section{Introdução}

As culturas de milho e sorgo têm sido as mais utilizadas no processo de ensilagem, por sua facilidade de cultivo, seus altos rendimentos e, especialmente, pela qualidade da silagem produzida sem necessidade de aditivo para estimular a fermentação (Zago, 1999). Valadares Filho et al. (2002), em trabalho de revisão, relataram que a silagem de milho tem 
proporcionado ganhos de peso consideráveis, tornando-se o volumoso mais aceito pelos pecuaristas dedicados à engorda de bovinos de corte. Estima-se que as áreas cultivadas com milho e sorgo para silagem ultrapassem um milhão de hectares e que $80 \%$ desse total corresponda à cultura do milho (Zago, 2002).

A produção de feno, no entanto, é pouco expressiva no Brasil. O censo Agropecuário de 1995-96 (IBGE, 2003) não registrou produção e valor de feno. Razões como a falta de tradição e o desconhecimento da técnica de fenação, o alto investimento em máquinas para a produção e o relevo, que dificulta a mecanização, contribuem para este fato. Entretanto, o Brasil Central apresenta condições topográficas favoráveis à produção de feno, embora, na maioria das vezes, a qualidade deste feno produzido seja bastante questionável.

Em sistemas de confinamento, nutricionistas ajustam a quantidade e a qualidade da ração com base nas exigências dos animais. O uso de combinações entre alimentos volumosos pode ser viável para otimização do consumo, melhorando a ingestão de nutrientes e, conseqüentemente, o ganho de peso dos animais. Segundo Souza et al. (2001), a associação de silagem de sorgo e pré-secado de capim-tifton 85 em diferentes proporções apresentou-se como boa alternativa de volumoso para terminação de bovinos de corte em confinamento, o que demonstra a possibilidade de redução nos custos de alimentação,visto que o pré-secado possui custo inferior ao da silagem de sorgo, possibilitando maior flexibilidade no programa de suplementação alimentar do rebanho na seca, seja quando utilizado como fonte única de volumoso seja em associação à silagem de sorgo. Essa alternativa proporcionaria ainda redução na área destinada ao cultivo de sorgo para a produção de silagem, liberando áreas para outros cultivos, como para produção de grãos (Pereira \& Ribeiro, 2001).

Cavalcante et al. (2004), avaliando o consumo, a digestibilidade e os parâmetros ruminais de bovinos Holandês $\mathrm{x}$ Zebu canulados no rúmen recebendo dietas com feno de capim-tifton 85 e silagem de milho em diferentes proporções no volumoso, concluíram que as dietas se equivaleram nutricionalmente.

Face à escassez de estudos sobre a utilização conjunta de uma ou mais fontes de volumoso, conduziu-se este trabalho objetivando avaliar o consumo e a digestibilidade dos nutrientes, o ganho de peso e a conversão alimentar em bovinos de corte recebendo dietas contendo níveis crescentes de silagem de milho em substituição ao feno de capim-tifton 85 .

\section{Material e Métodos}

O experimento foi realizado nas dependências da Central de Experimentação, Pesquisa e Extensão do Triângulo Mineiro - CEPET, da Universidade Federal de Viçosa, no período de maio a julho de 2001. Foram utilizados 19 animais mestiços Limousin (3/4 a 7/8), não-castrados, com peso vivo médio inicial de $301 \mathrm{~kg}$. Depois de pesados e vermifugados, os animais foram distribuídos em baias individuais $\left(10 \mathrm{~m}^{2}\right)$ com cocho coberto e bebedouro, em um delineamento inteiramente casualizado, com cinco animais para os tratamentos 2,3 e 4 e quatro para o tratamento 1 .

As dietas foram formuladas para conter $12,5 \%$ de PB, considerando-se relação volumoso:concentrado de 58:42. Como fonte de volumoso, utilizaram-se feno de capimtifton 85 e silagem de milho do híbrido AG 1051 (Agroceres) nas proporções 100:0; 68:32; 35:65 e 0:100, respectivamente, com base na MS, que constituíram os tratamentos 1, 2, 3 e 4. O milho foi estabelecido em áreas da CEPET, respeitando-se as recomendações de plantio do produtor de sementes. A correção do solo foi realizada com base na análise de solo e nas "Recomendações para o uso de corretivos e fertilizantes em Minas Gerais" (CFSEMG, 1989). A ensilagem do milho foi feita em silos tipo superfície quando os grãos atingiram o estádio farináceo-duro. $\mathrm{O}$ feno foi produzido em uma área ( 5 ha) estabelecida com capim-tifton 85 , efetuando-se o corte com uma segadeira de barra, a aproximadamente $5 \mathrm{~cm}$ do solo, quando o capim se encontrava em avançado estádio de maturidade (florescimento pleno). O enfardamento foi realizado no início da tarde do dia seguinte ao corte, utilizando-se uma enfardadeira para fardos retangulares de 10 a $12 \mathrm{~kg}$. Antes de ser fornecido aos animais, procedeu-se à picagem do feno em uma máquina utilizada para confecção de présecado com regulagem para partículas de aproximadamente $6 \mathrm{~cm}$ de comprimento.

As proporções dos ingredientes do concentrado en contram-se na Tabela 1. As composições bromatológicas da silagem de milho, do feno e do concentrado encontram-se na Tabela 2 e as das dietas na Tabela 3. Após um período de adaptação de 15 dias, foram realizados três períodos experimentais de 28 dias. Os animais foram pesados, após jejum de 16 horas, no início e no final do experimento, efetuando-se pesagens intermediárias ao final de cada período. O volumoso e o concentrado foram fornecidos misturados, metade às $8 \mathrm{~h}$ e metade às $15 \mathrm{~h}$, permitindo-se $10 \%$ de sobras. Durante o ensaio, foram coletadas amostras diárias dos alimentos fornecidos e das sobras, que formaram 
Tabela 1 - Participação dos ingredientes no concentrado Table 1 - Ingredient composition of the concentrate

\begin{tabular}{lc}
\hline $\begin{array}{l}\text { Ingrediente } \\
\text { Ingredient }\end{array}$ & $\begin{array}{r}\text { \% na matéria natural } \\
\% \text { on natural matter }\end{array}$ \\
\hline Fubá de milho (Corn meal) & 53,96 \\
Grão de soja moído (Ground soybean grain) & 42,96 \\
Fosfato bicálcico (Dicalcium phosphate) & 0,88 \\
Sal (Salt) & 0,66 \\
Calcário calcítico (Limestone) & 0,55 \\
Uréia (Urea) & 0,79 \\
Sulfato de amônia (Ammonia sulfate) & 0,10 \\
Premix ${ }^{1}$ (Mix) & 0,11 \\
\hline
\end{tabular}

$181,5 \%$ de sulfato de zinco (zinc sulfate); $17,52 \%$ de sulfato de cobre (copper sulfate); $0,48 \%$ de iodato de potássio (potassium iodate); $0,32 \%$ de selenito de sódio (sodium selenite); e $0,18 \%$ de sulfato de cobalto (cobalt sulfate).

Tabela 2 - Composição química (valores médios) do concentrado, do feno e da silagem de milho utilizados nas dietas experimentais (\% da MS), nitrogênio amoniacal $\left(\mathrm{N}-\mathrm{NH}_{3}\right)$ e $\mathrm{pH}$ da silagem de milho

Table 2 - Chemical composition (average values) of the concentrate, Tifton 85 hay, and corn silage (\% of DM), ammonia nitrogen $\left(\mathrm{NH}_{3}-\mathrm{N}\right)$ and $\mathrm{pH}$ of corn silage

\begin{tabular}{lccc}
\hline Item & $\begin{array}{c}\text { Concentrado } \\
\text { Concentrate }\end{array}$ & $\begin{array}{c}\text { Feno } \\
\text { Tifton } 85 \text { hay }\end{array}$ & $\begin{array}{c}\text { Silagem de milho } \\
\text { Corn silage }\end{array}$ \\
\hline MS $(\%)(D M, \%)$ & 89,69 & 86,28 & 29,90 \\
MO (OM) & 93,14 & 94,26 & 95,64 \\
PB (CP) & 23,25 & 4,71 & 7,22 \\
NIDN $(N D I N)$ & 4,59 & 54,45 & 24,88 \\
NIDA ${ }^{1}($ ADIN) & 3,99 & 21,67 & 12,30 \\
EE & 11,95 & 0,66 & 2,08 \\
CT (TC) & 57,94 & 88,89 & 86,34 \\
FDN (NDF) & 13,64 & 80,61 & 54,04 \\
FDNcp (NDFap) & 12,72 & 78,76 & 52,79 \\
CNF (NFC) & 44,30 & 8,28 & 32,30 \\
FDA (ADF) & 7,16 & 44,34 & 30,98 \\
FDAi (IADF) & 2,88 & 30,81 & 17,28 \\
HEM & 6,48 & 36,27 & 23,05 \\
LIG & 1,65 & 8,39 & 5,04 \\
N-NH ${ }_{3}^{1}$ & - & - & 2,73 \\
pH & - & - & 3,51 \\
\hline
\end{tabular}

$1 \%$ do $\mathrm{N}$ total (\% total $\mathrm{N}$ ).

uma amostra composta para cada período. As amostras compostas foram acondicionadas em sacos plás ticos identificados e armazenadas em freezer a $-18^{\circ} \mathrm{C}$.

Do $62 \underline{0}$ ao $66^{\circ}$ dia experimental, foram coletadas amostras dos alimentos fornecidos, das sobras e de fezes frescas dos animais. As coletas de fezes foram feitas antes da primeira alimentação, diretamente no piso (raspado diariamente, para que não houvesse contaminação com fezes secas, urina ou solo).

Ao final do período experimental, todas as amostras foram submetidas à pré-secagem em estufa de ventilação forçada a $65^{\circ} \mathrm{C}$, por 72 horas, processadas em moinho de faca tipo Willey, com peneira de 30 mesh e armazenadas em recipientes de vidro com tampa de polietileno para futuras análises laboratoriais.
Tabela 3 - Composição química (valores médios) das dietas experimentais (\% da MS)

Table 3 - Chemical composition (average values) of the experimental diets (\% of DM)

\begin{tabular}{|c|c|c|c|c|}
\hline \multirow[t]{2}{*}{$\begin{array}{l}\text { Parâmetro } \\
\text { Item }\end{array}$} & \multicolumn{4}{|c|}{$\begin{array}{l}\text { Nível de silagem de milho no volumoso } \\
\text { Level of corn silage in the forage portion (\%) }\end{array}$} \\
\hline & 0 & 32 & 65 & 100 \\
\hline $\operatorname{MS}(\%)(D M, \%)$ & 88,27 & 77,04 & 65,53 & 53,35 \\
\hline $\mathrm{MO}(O M)$ & 93,79 & 94,05 & 94,32 & 94,60 \\
\hline $\mathrm{PB}(C P)$ & 12,42 & 12,89 & 13,38 & 13,89 \\
\hline $\mathrm{NIDN}^{1}(N D I N)$ & 12,10 & 10,54 & 9,05 & 7,59 \\
\hline $\operatorname{NIDA}^{1}(A D I N)$ & 4,81 & 4,44 & 4,09 & 3,74 \\
\hline EE & 5,36 & 5,62 & 5,90 & 6,19 \\
\hline $\mathrm{CT}(T C)$ & 76,01 & 75,53 & 75,04 & 74,52 \\
\hline $\operatorname{FDN}(N D F)$ & 52,75 & 47,76 & 42,64 & 37,23 \\
\hline FDNcp (NDFap) & 51,29 & 46,41 & 41,41 & 36,12 \\
\hline $\mathrm{CNF}(N F C)$ & 23,26 & 27,77 & 32,40 & 37,29 \\
\hline FDA $(A D F)$ & 28,88 & 26,37 & 23,79 & 21,07 \\
\hline FDAi $(I A D F)$ & 19,19 & 16,65 & 14,05 & 11,29 \\
\hline HEM & 23,88 & 21,39 & 18,85 & 16,16 \\
\hline LIG & 5,58 & 4,95 & 4,31 & 3,63 \\
\hline $\operatorname{NDT}(T D N)$ & 63,33 & 64,15 & 64,96 & 69,56 \\
\hline
\end{tabular}

$1 \%$ do $\mathrm{N}$ total (\% total $\mathrm{N}$ ).

Ao final do experimento, todas as amostras foram transportadas para o Laboratório de Nutrição Animal do Departamento de Zootecnia da UFV, em Viçosa. As análises laboratoriais foram realizadas segundo procedimentos descritos por Silva \& Queiroz (2002). Os carboidratos totais (CT) foram calculados segundo metodologia da Universidade de Cornell, descrita por Sniffen et al. (1992), em que $\mathrm{CT}(\%)=100-(\% \mathrm{~PB}+\% \mathrm{EE}+\%$ Cinzas $)$, e o NDT dos alimentos, segundo equação proposta por Weiss (1999): $\mathrm{NDT}=\mathrm{PBD}+2,25 \times \mathrm{EED}+\mathrm{FDNcpD}+\mathrm{CNFD}$, em que PBD, EED, FDN e CNFD significam, respectivamente, PB digestível, EE digestível, FDN digestível e CNF digestíveis. Os CNF foram calculados por meio da diferença entre CT e FDN.

O indicador interno fibra em detergente ácido insolúvel (FDAi) foi utilizado para estimar a produção de MS fecal (MSF), conforme proposto por Cochran et al. (1986). Entretanto, as amostras compostas de alimentos fornecidos, sobras e fezes foram incubadas no rúmen (in situ) em sacos de ankom (filter bags 57), por 144 horas, em vez de se utilizar a digestibilidade in vitro sugerida pelos autores. O material resultante dessa incubação foi submetido à digestão com detergente ácido e o resíduo foi considerado FDAi. O total de MSF foi calculado segundo a equação: $\mathrm{kg}$ de MSF estimada $=\mathrm{kg}$ de indicador ingerido $/ \%$ do indicador nas fezes.

Os dados foram submetidos às análises de variância e regressão, utilizando-se o programa SAEG - Sistema de análises estatísticas e genéticas, versão 8.0 (UFV, 2000). Os modelos foram escolhidos com base na significância dos coeficientes de regressão, utilizando-se o teste t, adotando-se 
o nível de 5 a $1 \%$ de probabilidade, no coeficiente de determinação e no fenômeno biológico.

\section{Resultados e Discussão}

O consumo de MS, expresso nas diferentes formas (Tabela 4), foi influenciado de forma quadrática pela proporção de silagem de milho no volumoso, estimando-se valores máximos de 7,52 kg/dia e 2,14\% do PV, para dietas contendo 61,13 e 55,02\% de silagem de milho no volumoso, respectivamente. Segundo o NRC (1996), o consumo de MS em animais desta categoria deveria ser de $7,8 \mathrm{~kg} / \mathrm{dia}$. O mais baixo consumo observado pode estar relacionado ao alto teor de EE das dietas (Tabela 3), causando diminuição da digestibilidade da fibra e, conseqüentemente, aumento na retenção do bolo alimentar (Staples et al., 2001). Cavalcante et al. (2004), em ensaio com bovinos mestiços (Holandês x Zebu) canulados no rúmen, forneceram as mesmas dietas deste ensaio, em quantidade para proporcionar $10 \%$ de sobras, e não observaram diferenças no consumo de MS, obtendo valores médios de 9,2 kg/dia e 1,7\% do PV.

Nelson \& Satter (1992), em ensaio com vacas leiteiras, relataram que dietas à base de feno estão mais sujeitas a limitações de consumo pelo enchimento ruminal, sob demandas semelhantes de energia, que dietas à base de silagem, em decorrência da maior solubilidade dos nutrientes da silagem. O consumo de feno pode ser limitado pela quantidade de saliva necessária para seu umedecimento e posterior deglutição (Luginbuhl et al., 2000). O consumo de MS mais baixo na dieta contendo apenas feno pode estar associado também ao maior teor de FDAI deste alimento em relação à silagem de milho (Tabela 2). Todavia, o consumo de silagem pode ser limitado pelos produtos da fermentação, por mudanças na estrutura física do material ensilado, pela quebra de proteína na forma de amônia e pela redução do $\mathrm{pH}$. Desta forma, a associação destes dois volumosos pode ser uma alternativa para minimização destes problemas, mas parece não ser aplicável a este trabalho, face à ótima qualidade da silagem produzida, comprovada pelas características visuais e pelos baixos valores de $\mathrm{pH}$ e $\mathrm{N}-\mathrm{NH}_{3}$ (Tabela 2).

O consumo de MO expresso nas diferentes formas foi influenciado de forma quadrática pela proporção de silagem de milho no volumoso, apresentando valores máximos de $7,08 \mathrm{~kg} / \mathrm{dia}$ e $2,02 \% \mathrm{PV}$ para dietas contendo 61,78 e 55,77\% de silagem de milho no volumoso, respectivamente.

Tabela 4 - Consumos médios diários de nutrientes da dieta, coeficientes de variação (CV) e respectivas equações de regressão, ajustadas em função da proporção de silagem de milho no volumoso (SM) nas dietas, e coeficientes de determinação $\left(r^{2} / R^{2}\right)$

Table 4 - Average daily nutrient intakes, coefficients of variation $(\mathrm{CV})$, regression equations in function of the proportion of corn silage in the forage portion (SM) of the diet, and coefficients of determination $\left(r^{2} / R^{s}\right)$

\begin{tabular}{|c|c|c|c|c|c|c|c|}
\hline \multirow[t]{2}{*}{$\begin{array}{l}\text { Item } \\
\text { Item }\end{array}$} & \multicolumn{4}{|c|}{$\begin{array}{l}\text { Nível de silagem de milho no volumoso (\%) } \\
\text { Level of corn silage in the forage portion }(\%)\end{array}$} & \multirow[t]{2}{*}{$\mathrm{CV}(\%)$} & \multirow[t]{2}{*}{$\begin{array}{l}\text { Equação } \\
\text { Equation }\end{array}$} & \multirow[t]{2}{*}{$r^{2} / R^{2}$} \\
\hline & 0 & 32 & 65 & 100 & & & \\
\hline $\operatorname{MS}(D M)$ & 6,14 & 7,26 & 7,47 & 6,98 & 10,68 & $\hat{y}=6,16111+0,04439^{\text {ns }} S M-0,0003632 * S M^{2}$ & 0,99 \\
\hline $\mathrm{PB}(C P)$ & 0,81 & 1,01 & 1,07 & 1,05 & 10,07 & $\hat{\mathrm{y}}=0,81926+0,00729 * \mathrm{SM}-0,0000506 * \mathrm{SM}^{2}$ & 0,99 \\
\hline $\mathrm{EE}$ & 0,36 & 0,45 & 0,49 & 0,49 & 9,90 & $\hat{\mathrm{y}}=0,388344+0,00120541 * \mathrm{SM}$ & 0,79 \\
\hline $\mathrm{CT}(T C)$ & 4,58 & 5,36 & 5,48 & 5,06 & 10,92 & $\hat{\mathrm{y}}=4,5924+0,031776^{\mathrm{ns}} \mathrm{SM}-0,0002719^{*} \mathrm{SM}^{2}$ & 0,99 \\
\hline $\mathrm{FDN}(N D F)$ & 3,07 & 3,19 & 2,91 & 2,31 & 11,29 & $\hat{\mathrm{y}}=3,07568+0,008017 * * \mathrm{SM}-0,0001576 * \mathrm{SM}^{2}$ & 0,72 \\
\hline \multicolumn{8}{|c|}{$\begin{array}{c}\text { Consumo }(\% \mathrm{PV}) \\
\text { Intake }(\% B W)\end{array}$} \\
\hline $\mathrm{MS}(D M)$ & 1,86 & 2,06 & 2,16 & 1,93 & 7,82 & $\hat{\mathrm{y}}=1,84268+0,0108^{\mathrm{ns}} \mathrm{SM}-0,0000985^{* *} \mathrm{SM}^{2}$ & 0,95 \\
\hline $\mathrm{MO}(O M)$ & 1,74 & 1,93 & 2,04 & 1,82 & 7,83 & $\hat{\mathrm{y}}=1,7264+0,0104^{\mathrm{ns}} \mathrm{SM}-0,00009339^{*} * \mathrm{SM}^{2}$ & 0,95 \\
\hline $\mathrm{FDN}(N D F)$ & 0,93 & 0,90 & 0,84 & 0,64 & 8,66 & $\hat{\mathrm{y}}=0,972968-0,00290095 * \mathrm{SM}$ & 0,83 \\
\hline
\end{tabular}

* $(\mathrm{P}<0,05) ;{ }^{* \star}(\mathrm{P}<0,01)$ 
De forma similar, foram observadas respostas quadráticas para os consumos de PB e CT, sendo estimados valores máximos de 1,08 e $5,52 \mathrm{~kg} /$ dia para dietas contendo 72,23 e $58,45 \%$ de silagem de milho no volumoso, respectivamente. Cavalcante et al. (2004) observaram consumos médios de 1,1 e 7,3 kg/dia para os respectivos nutrientes, os quais foram superiores aos verificados neste ensaio. $\mathrm{O}$ consumo de $\mathrm{PB}$ atendeu às exigências para animais desta categoria, que, segundo o NRC (1996), são de 0,87 e 0,95 kg/ dia para ganhos de 1,0 e 1,2 kg/dia, respectivamente, exceto para animais que receberam dietas contendo $0 \%$ de silagem de milho no volumoso.

Verificou-se aumento linear do consumo de EE com o incremento da proporção de silagem de milho no volumoso. Fato semelhante foi observado por Cavalcante et al. (2004). $\mathrm{O}$ consumo de $\mathrm{CNF}$ aumentou $0,012 \mathrm{~kg}$ por unidade de acréscimo de silagem de milho, o que pode ser explicado pelo maior teor destes nutrientes nas dietas contendo silagem de milho em relação ao feno (Tabela 3 ).

O consumo de FDN expresso em kg/dia apresentou resposta quadrática com o aumento da proporção de silagem de milho na dieta, estimando-se consumo máximo de $3,18 \mathrm{~kg} /$ dia para dietas contendo $25,44 \%$ de silagem de milho no volumoso. O consumo de FDN expresso como \% do PV, no entanto, diminuiu 0,003 unidades por unidade de acréscimo de silagem de milho, como resultado da diminuição deste nutriente com o aumento da proporção de silagem de milho nas dietas (Tabela 3). Cavalcante et al. (2004) não observaram diferenças no consumo de FDN com o aumento da participação de silagem de milho no volumoso.

Ribeiro et al. (2001) e Athaíde Jr. et al. (2001), trabalhando com bovinos recebendo dietas contendo fenos de capim-tifton 85 , de diferentes idades de rebrota, na proporção de $60 \%$ da dieta, registraram consumo médio de FDN de 0,98\%PV, próximo aos 0,93 \% PV observado neste ensaio em animais recebendo dietas apenas com feno de capim-tifton 85 .

O consumo de NDT aumentou linearmente com o incremento da proporção de silagem de milho no volumoso, registrando-se aumento de $0,006 \mathrm{~kg}$ por unidade de acréscimo de silagem de milho (Tabela 4).

As digestibilidades aparentes da MS e MO não foram influenciadas pelas proporções de silagem de milho no volumoso das dietas experimentais, sendo registrados, respectivamente, valores médios de 62,8 e 63,07\% (Tabela 5). Possivelmente, o menor consumo da dieta contendo apenas feno de capim-tifton 85 proporcionou maior tempo de retenção ruminal e, conseqüentemente, maior digestibilidade numérica desses nutrientes em relação à dieta com $32 \%$ de silagem de milho.

Ribeiro et al. (2001) e Cavalcante et al. (2004) não observaram diferenças entre as digestibilidades aparentes da MS e MO, mas registraram valores superiores aos encontrados para estas variáveis neste ensaio.

A digestibilidade aparente da PB foi influenciada de forma quadrática pela proporção de silagem de milho no volumoso, estimando-se valor mínimo de $66,07 \%$ para dietas contendo $65,30 \%$ de silagem de milho no volumoso. Por sua vez, a digestibilidade aparente do EE diminuiu linearmente com o aumento da proporção de silagem de milho no volumoso, registrando-se decréscimos de 0,172 unidades por unidade de acréscimo de silagem de milho (Tabela 5).

As digestibilidades aparentes dos CT e dos CNF au mentaram linearmente com o incremento da proporção de

Tabela 5 - Médias, coeficientes de variação (CV), respectivas equações de regressão ajustadas em função da proporção de silagem de milho no volumoso (SM) nas dietas e coeficientes de determinação $\left(\mathrm{r}^{2} / \mathrm{R}^{2}\right)$ para as digestibilidades aparentes dos nutrientes

Table 5 - Means, coefficients of variation (CV), regression equations in function of the proportion of corn silage in the forage portion (SM) of the diet, and coefficients of determination $\left(r^{2} / R^{2}\right)$ for the apparent total tract nutrient digestibilities

\begin{tabular}{|c|c|c|c|c|c|c|c|}
\hline \multirow[t]{2}{*}{$\begin{array}{l}\text { Item } \\
\text { Item }\end{array}$} & \multicolumn{4}{|c|}{$\begin{array}{l}\text { Nível de silagem de milho no volumoso }(\%) \\
\text { Level of corn silage in the forage portion }(\%)\end{array}$} & \multirow[t]{2}{*}{$\mathrm{CV}(\%)$} & \multirow[t]{2}{*}{$\begin{array}{l}\text { Equação } \\
\text { Equation }\end{array}$} & \multirow[t]{2}{*}{$\mathrm{r}^{2} / \mathrm{R}^{2}$} \\
\hline & 0 & 32 & 65 & 100 & & & \\
\hline $\operatorname{MS}(D M)$ & 63,12 & 60,54 & 62,74 & 64,82 & 6,47 & $\hat{y}=62,80$ & \\
\hline $\mathrm{MO}(O M)$ & 63,62 & 60,79 & 62,85 & 65,03 & 6,44 & $\hat{y}=63,07$ & \\
\hline $\mathrm{PB}(C P)$ & 74,57 & 65,84 & 66,94 & 67,03 & 6,36 & $\hat{\mathrm{y}}=73,835-0,258409 * \mathrm{SM}+0,00196 * \mathrm{SM}^{2}$ & 0,86 \\
\hline $\mathrm{CT}(T C)$ & 60,09 & 59,31 & 61,58 & 64,71 & 5,97 & $\hat{y}=58,842+0,0510997 * S M$ & 0,77 \\
\hline $\mathrm{FDN}(N D F)$ & 52,45 & 50,71 & 48,49 & 48,40 & 5,10 & $\hat{y}=50,01$ & \\
\hline $\mathrm{CNF}(N F C)$ & 74,39 & 72,38 & 77,66 & 80,35 & 8,95 & $\hat{\mathrm{y}}=72,4757+0,0734301 * * \mathrm{SM}$ & 0,73 \\
\hline
\end{tabular}

* $(\mathrm{P}<0,05) ;{ }^{* *}(\mathrm{P}<0,01)$ 
silagem de milho no volumoso, registrando-se, respectivamente, acréscimos de 0,051 e 0,073 unidades por unidade de acréscimo de silagem de milho (Tabela 5), possivelmente em decorrência do aumento da ingestão de EE.

A digestibilidade aparente da FDN (média de 50,01\%) não foi influenciada pelos níveis de silagem de milho no volumoso. Segundo Beauchemin \& Buchanan-Smith (1990), dietas contendo silagem resultam em maiores digestibilidades que aquelas contendo feno, pois, no decorrer da digestão, geralmente ocorre, em menor tempo, maior desintegração das partículas da silagem, resultando em maior taxa de passagem. Assim, é possível que a taxa de passagem da dieta com $100 \%$ de silagem de milho no volumoso seja maior que as de dietas com feno, haja vista a maior velocidade de degradação do material. Entretanto, isso pode facilitar o escape de material potencialmente digestível, que, com menores taxas de passagem, pode ser mais bem digerido e aproveitado. Com base nestas colocações e nos dados constantes na Tabela 5, pode-se afirmar que, em valores numéricos, a digestibilidade da FDN foi superior para as dietas com maiores teores de feno no volumoso.

Cavalcante et al. (2004), avaliando dietas semelhantes às deste ensaio, estimaram taxas de passagem da digesta de 4,$0 ; 4,0 ; 4,23$ e 4,40\%/hora para dietas contendo $0,33,67$ e

Tabela 6 - Médias de ganho de peso (GMD) e conversão alimentar (CA), coeficientes de variação (CV), respectivas equações de regressão, ajustadas em função da proporção de silagem de milho no volumoso (SM) nas dietas, e coeficientes de determinação $\left(\mathrm{r}^{2}\right)$

Table 6 - Means of weight gain (WG), feed conversion (FC), coefficients of variation (CV), regression equations in function of the proportion of corn silage in the forage portion (SM) of the diet, and coefficients of determination $\left(r^{2}\right)$

\begin{tabular}{|c|c|c|c|c|c|c|c|}
\hline \multirow[t]{2}{*}{$\begin{array}{l}\text { Item } \\
\text { Item }\end{array}$} & \multicolumn{4}{|c|}{$\begin{array}{l}\text { Nível de silagem de milho no volumoso }(\%) \\
\text { Level of corn silage in the forage portion }(\%)\end{array}$} & \multirow[t]{2}{*}{$\mathrm{CV}(\%)$} & \multirow[t]{2}{*}{$\begin{array}{l}\text { Equação } \\
\text { Equation }\end{array}$} & \multirow[t]{2}{*}{$r^{2}$} \\
\hline & 0 & 32 & 65 & 100 & & & \\
\hline $\begin{array}{l}\text { GMD }(\mathrm{kg} / \mathrm{dia}) \\
W G(\mathrm{~kg} / \text { day })\end{array}$ & 0,77 & 1,16 & 1,22 & 1,29 & 11,88 & $\hat{\mathrm{y}}=0,874495+0,00482 * * \mathrm{SM}$ & 0,79 \\
\hline $\begin{array}{l}\mathrm{CA} \\
F C\end{array}$ & 7,98 & 6,26 & 6,16 & 5,46 & 10,57 & $\hat{y}=7,53623-0,022116 * * S M$ & 0,84 \\
\hline
\end{tabular}

$100 \%$ de silagem de milho no volumoso. Esta menor taxa de passagem para dieta contendo apenas feno pode levar a maior digestibilidade, fazendo com que as digestibilidades aparentes da FDN se tornem equivalentes entre as dietas.

Na Tabela 6 são apresentadas as médias de ganhos de peso (GMD) e conversão alimentar (CA), os respectivos coeficientes de variação e determinação e as equações de regressão, obtidas em função dos diferentes níveis de silagem de milho no volumoso da dieta. O GMD aumentou linearmente com a adição de silagem de milho nas dietas, estimando-se incrementos de $0,00482 \mathrm{~kg}$ por unidade de acréscimo de silagem de milho, provavelmente ocasionados pelo consumo de NDT (Tabela 4). Ressalta-se também o fato de que o teor de PB ter aumentado e os de NIDN e NIDA diminuído (Tabela 3) com a adição de silagem de milho nas dietas. Chizzotti et al. (2005) também observaram aumento linear no GMD com a adição de silagem de sorgo em substituição à silagem de Brachiaria brizantha em dietas para bovinos de corte.

Gesualdi Jr. et al. (2000), em ensaio de desempenho com animais F1 Limousin x Nelore consumindo feno de capim-coastcross como única fonte de volumoso e dife- rentes níveis de concentrado, obtiveram GMD máximo de $1,16 \mathrm{~kg} /$ dia no nível de $61,11 \%$ de concentrado, enquanto, com $37,5 \%$ de concentrado, o GMD foi de 1,03 kg/dia. Este valor é superior ao de $0,77 \mathrm{~kg} / \mathrm{dia}$ obtido nas dietas com $100 \%$ de fenoe provavelmente foi ocasionado pela baixa qualidade do feno utilizado neste experimento (Tabela 2).

A conversão alimentar melhorou linearmente com o aumento da proporção de silagem de milho nas dietas, estimando-se decréscimos de 0,022 unidades por unidade de acréscimo de silagem de milho. A conversão alimentar para animais Holandês x Zebu recebendo silagem de milho e diferentes níveis de concentrado foi em média de 7,81 (Souza et al., 2002), superior à de 5,46 encontrada neste ensaio para animais recebendo exclusivamente silagem de milho, como conseqüência do maior potencial genético destes animais, especialmente para deposição de músculo, por serem animais mais tardios para deposição de gordura.

Considerando os resultados obtidos, pode-se inferir que a silagem de milho, associada ao feno de capim-tifton 85 de baixa qualidade, apresentou-se como boa fonte de volumoso para animais em confinamento, pois favoreceu o consumo de nutrientes e o ganho de peso dos animais em 
relação àqueles alimentados com $100 \%$ de feno como volumoso na dieta. Essa associação evidencia a possibilidade de otimização do uso da terra, com redução da área para produção de silagem e aumento de áreas cultivadas para a produção de grãos, ou outras atividades, conforme sugerido por Pereira \& Ribeiro (2001).

\section{Conclusões}

A silagem de milho na proporção de $61 \%$ do volumoso da dieta proporcionou máximo consumo de MS. O ganho de peso aumentou 4,82 g/dia para cada unidade de silagem de milho adicionada ao volumoso da dieta para novilhos mestiços Limousin, indicando que não houve vantagem da combinação feno x silagem sobre o ganho de peso em comparação à dieta contendo apenas silagem de milho como volumoso.

\section{Literatura Citada}

ATHAÍDE JR., J.R.; PEREIRA, O.G.; VALADARES FILHO, S.C. et al. Consumo, digestibilidade e desempenho de novilhos alimentados com ração à base de capim-tifton 85 (Cynodon spp.), em diferentes idades de rebrota. Revista Brasileira de Zootecnia, v.30, n.1, p.215-221, 2001.

BEACHEMIN, K.A.; BUCHANAN-SMITH, J.G. Effects of fiber source and method of feeding on chewing activities, digestive function, and productivity of dairy cows. Journal of Dairy Science, v.73, n.3, p.749-762, 1990.

CAVALCANTE, A.C.R.; PEREIRA, O.G.; VALADARES FILHO, S.C. et al. Dietas contendo silagem de milho (Zea mays L.) e feno de capim-Tifton 85 (Cynodon spp.) em diferentes proporções para bovinos. Revista Brasileira de Zootecnia, v.33, n.6, p.2394-2402, 2004 (supl. 3).

CHIZZOTTI, F.H.M; PEREIRA, O.G.; VALADARES FILHO, S.C. et al. Consumo, digestibilidade total e desempenho de novilhos Nelore recebendo dietas contendo diferentes proporções de silagens de Brachiaria brizantha cv. Marandu e de sorgo. Revista Brasileira de Zootecnia, v.34, n.6, p.2427-2436, 2005.

COMISSÃO DE FERTILIDADE DO SOLO DO ESTADO DE MINAS GERAIS - CFSEMG. Recomendações para uso de corretivos e fertilizantes em Minas Gerais. 4a Aproximação. Lavras: 1989. 159p.

COCHRAN, R.C.; ADAMS, D.C.; WALACE, J.D. et al. Predicting digestibility of different diets with internal markers: Evaluation of four potential markers. Journal of Animal Science, v.63, n.5, p.1476-1483, 1986.

INSTITUTO BRASILEIRO E GEOGRAFIA E ESTATÍSTICA IBGE. Censo Agropecuário 1995-1996. Disponível em: <http://www.sidra.ibge.gov.br/bda/agric/> Acesso em: 25/07/2003.

GESUALDI JR., A.; PAULINO, M.F.; VALADARES FILHO, S.C. et al. Níveis de concentrado na dieta de novilhos F1 Limousin $x$ Nelore: consumo, conversão alimentar e ganho de peso. Revista Brasileira de Zootecnia, v.29, n.5, p.1458-1466, 2000.

LUGINBUHL, J.M.; POND, K.R.; BURNS, J.C. et al. Intake and chewing behavior of steers consuming switchgrars preserved as hay or silage. Journal of Animal Science, v.78, n.7, p.1983-1989, 2000.

NATIONAL RESEARCH COUNCIL - NRC. Nutrient requirements of beef cattle. 7.ed. Washington, D.C.: National Academy, 1996. $242 p$.
NELSON, W.F.; SATTER, L.D. Impact of stage of maturity and mathods of preservation of alfafa on digestion in lactation dairy cows. Journal of Dairy Science, v.75, n.6, p.1571, 1992.

PEREIRA, O.G.; RIBEIRO, K.G. Suplementação de bovinos com forragens conservadas. In: SIMPÓSIO DE PRODUÇÃO DE GADO DE CORT E, 2., 2001, Viçosa, MG. Anais... Viçosa, MG: Universidade Federal de Viçosa, 2001. p.261-289.

RIBEIRO, K.G.; PEREIRA, O.G.; GARCIA, R. et al. Consumo e digestibilidade aparente total e parcial de nutrientes, em bovinos recebendo rações contendo feno de capim-tifton 85 de diferentes idades de rebrota. Revista Brasileira de Zootecnia, v.30, n.2, p.573-580, 2001.

SILVA, D.J.; QUEIROZ, A.C. Análise de alimentos (Métodos químicos e biológicos). 3.ed. Viçosa, MG: Universidade Federal de Viçosa, 2002. 235p.

SNIFFEN, C.J.; O'CONNOR, J.D.; Van SOEST, P.J. et al. A net carbohydrate and protein system for evaluating cattle diets. II. Carbohydrate and protein availability. Journal of Animal Science, v.70, n.11, p.3562-3577, 1992.

SOUZA, V.G; PEREIRA, O.G.; VALADARES FILHO, S.C. et al. Consumo e desempenho de bovinos de corte recebendo dietas contendo silagem de milho e concentrado em diferentes proporções In: REUNIÃO ANUAL DA SOCIEDADE BRASILEIRA DE ZOOTECNIA, 39., 2002, Recife. Anais... Recife: Sociedade Brasileira de Zootecnia, 2002. (CD-ROM)

SOUZA, V.G.; PEREIRA, O.G.; VALADARES FILHO, S.C. et al. Consumo, ganho de peso e conversão alimentar de bovinos de corte recebendo rações contendo silagem de sorgo e pré-secado de capim-tifton 85. In: REUNIÃO ANUAL DA SOCIEDADE BRASILEIRA DE ZOOTECNIA, 38., 2001, Piracicaba. Anais... Piracicaba: Sociedade Brasileira de Zootecnia, 2001. (CD-ROM)

STAPLES, C.; THATCHER, W.W.; MATOS, R. Estratégias de suplementação de gordura em dietas de vacas em lactação. In: SINLEITE - SIMPÓSIO INTERNACIONAL EM BOVINOCULTURA DE LEITE - Novos Conceitos em Nutrição, 2., 2001, Lavras. Anais... Lavras: Universidade Federal de Lavras, 2001. p.179-197.

UNIVERSIDADE FEDERAL DE VIÇOSA - UFV. Sistema de análises estatísticas e genéticas - SAEG . Versão 8.0. Viçosa, MG: 2000. 142p.

VALADARES FILHO, S.C.; PAULINO, P.V.R.; MAGALHÃES, K.A. et al. Modelos nutricionais alternativos otimização da renda na produção de bovinos de corte. In: SIMPÓSIO DE PRODUÇÃO DE GADO DE CORTE, 3., 2002, Viçosa, MG. Anais... Viçosa, MG: Universidade Federal de Viçosa, 2002. p.197-254.

ZAGO, C.P. Híbridos de milho e sorgo para silagem: características agronômicas e nutricionais.In: SIMPÓSIO SOBRE MANEJO ESTRATÉGICO DE PASTAGENS, 1., 2002, Viçosa, MG. Anais... Viçosa, MG: Universidade Federal de Viçosa, 2002. p. 351-350.

ZAGO, C.P. Silagem de sorgo. In.: SIMPÓSIO SOBRE NUTRIÇÃO DE BOVINOS, 7., 1999, Piracicaba. Anais... Piracicaba: Fundação de Estudos Agrários Luiz de Queiroz, 1999. p.47-68.

WEISS, W. Energy prediction equations for ruminant feeds. In: CORNELL NUTRITION CONFERENCE FOR FEED MANUFACTURERS, 61., 1999, Ithaca. Proceedings... Ithaca: Cornell University, 1999. p.176-185. 